\title{
Evaluation of specific quality metrics to assess the performance of a specialised newborn transport programme
}

\author{
Itziar Marsinyach Ros ${ }^{1} \cdot$ Laura Sanchez García ${ }^{2}$. Ana Sanchez Torres ${ }^{2} \cdot$ Rocio Mosqueda Peña ${ }^{3}$. \\ Maria del Carmen Pérez Grande ${ }^{3}$ - Maria José Rodríguez Castaño ${ }^{4}$ Maria Dolores Elorza Fernández ${ }^{2}$. \\ Manuel Sánchez Luna ${ }^{1}$
}

Received: 15 May 2019 / Revised: 20 December 2019 / Accepted: 10 January 2020 / Published online: 28 January 2020

(C) Springer-Verlag GmbH Germany, part of Springer Nature 2020

\begin{abstract}
There is a lack of consensus on quality indicators suitable for neonatal transport. The aim of this study is to make a proposal for specific quality indicators for newborn transport. A retrospective descriptive study was performed (2009 to 2015) where twenty-four indicators were selected, evaluated and classified according to the 6 dimensions of quality of the Institute of Medicine. Among the 24 evaluated quality metrics, there were 3 of them which needed a correction when evaluating neonatal transport performance, because they were significantly correlated with gestational age. They were (a) stabilisation time, (b) prevalence of newborn arterial hypotension (defined by gestational age) and (c) unnoticed hypothermia at referral hospital.

Conclusion: Quality evaluation through the definition of specific metrics in newborn transport is feasible. These indicators should be defined or adjusted for newborn population to measure the actual performance of the transport service.
\end{abstract}

What is Known:

- Quality indicators may help in defining metrics for clinical practice, promoting benchmarking and defining areas of improvement.

- Newborn characteristics call for a specialised care, and quality measure during newborn transport require specific metrics. Quality metrics for paediatric transport have been defined using Delphi method. Some of these measures need to be specific for newborn, due to their intrinsic characteristics.

What is New:

- Using evidence-based literature and our newborn transport experience, specific quality indicators for newborn transport are suggested.

- Data analysis shows how some indicators need to be adjusted for gestational age.

Keywords Quality improvement · Newborn · Transport · Indicators · Metrics

Communicated by Patrick Van Reempts

Itziar Marsinyach Ros

itziar.marsinyach@salud.madrid.org; icimarsinyach@hotmail.com

Laura Sanchez García

laurasg_alcobendas@yahoo.es

Ana Sanchez Torres

anasancheztorres@gmail.es

Rocio Mosqueda Peña

romospe@hotmail.com

Maria del Carmen Pérez Grande

menchuperezgrande@gmail.es

Maria José Rodríguez Castaño

mariyou100@hotmail.com
1 Newborn Specialized Transport Madrid (SUMMA 112), Neonatology Department, Gregorio Marañón Hospital, O’Donnell 48 Street, 28009 Madrid, Spain

2 Newborn Specialized Transport Madrid (SUMMA 112), Neonatology Department, Hospital Universitario La Paz, Madrid, Spain

3 Newborn Specialized Transport Madrid (SUMMA 112), Neonatology Department, Hospital Universitario 12 de Octubre, Madrid, Spain

4 Newborn Specialized Transport Madrid (SUMMA 112), Neonatology Department, Hospital Clínico San Carlos, Madrid, Spain 


$\begin{array}{ll}\text { Abbreviations } & \\ \text { AE } & \text { Adverse events } \\ \text { AAP } & \text { American Academy of } \\ & \text { Pediatrics } \\ \text { CI } & \text { Confidence interval } \\ \text { HMD } & \text { Health and Medicine Division } \\ \text { NICU } & \text { Neonatal intensive care unit } \\ \text { NTT } & \text { Neonatal transport team } \\ \text { OR } & \text { Odds ratio } \\ \text { SD } & \text { Standard deviation } \\ \text { SOTM } & \text { Section on Transport Medicine } \\ \text { SQUIRE guidelines } & \text { Standards for Quality } \\ & \text { Improvement Reporting } \\ & \text { Excellence guidelines } \\ \text { TRIPS-II } & \text { Transport Risk Index Physiologic } \\ & \text { Stability version II }\end{array}$

\section{Introduction}

Perinatal health care regionalisation of care calls for an organised neonatal retrieval service $[26,41]$. The aims of a quality control programme in newborn transport are similar to those in other areas of medicine: measure the service's performance, prevent adverse events and progress to continuous improvement, amongst others [14, 15, 38]. Nevertheless, due to the intrinsic characteristics of inter-hospital transport [2], quality assessment can be challenging [24]. Moreover, many newborn transport models coexist, with variations on team composition, resources and training [22, 26, 39]. Performance measures in other areas of medicine, such as emergency medicine, critical care and neonatology, are already defined [31,35], but consensus on the ideal indicators solely for neonatal transport lack at the moment. Scientific societies, like the American Academy of Pediatrics (AAP) and Section on Transport Medicine (SOTM), and recent guidelines $[36,41,46]$ emphasise the need to measure indicators in newborn transport. To date, some studies have approached the subject [21,32], suggesting the use of quality indicators applied to paediatric transport but not exclusive for newborns.

The primary aim of this study is to make a proposal for quality indicators for newborn transport and to evaluate the feasibility of their use, assessing their performance through time in a specialised newborn retrieval service: newborn transport programme of Madrid (SUMMA 112). A secondary aim of the study is to evaluate the possible influence of factors only applicable to newborn population that might affect the measures or the outcomes.

SQUIRE guidelines (Standards for Quality Improvement Reporting Excellence guidelines) were followed when preparing the manuscript [40].

\section{Patients and methods}

A retrospective descriptive study was performed. The study included every patient that was retrieved by the newborn transport programme of Comunidad de Madrid from 2009 to 2015.

This transport programme is activated if retrieval is needed for any patient less than 29 days old or less than 44 weeks of post-conceptual age. Data were collected from the transport medical charts of all newborns retrieved during the study period.

\section{Newborn transport system organisation}

In Spain, out of its 17 administrative regions, each with an independent public health care management, only 4 of them provide a specialised newborn-paediatric inter-hospital transport system, Comunidad of Madrid being one of them. The newborn health care in the region of Madrid is a highly regionalised network comprised by 4 maximum level of care hospitals (IIIB-C [34], IIIA and II level hospitals) and private maternity centres up to 44 potential points of referral. It covers an area of $8021.80 \mathrm{~km}^{2}$ and a population of $6,377,364$ (19.80\% of Spain's population). The birth rate in Comunidad de Madrid in the last 5 years remained stable, approximately 10.16 newborns per 1000 inhabitants [20].

The Madrid Newborn Transport System is a full-time specialised retrieval system with coverage of the whole region resulting in the cooperation of the hospital newborn consultants and the emergency services: "Servicio de Urgencias Médicas de Madrid (SUMMA 112)". A dedicated newborn transport consultant, that belongs to one of the 4 maximum newborn level hospitals with specific training in newborn critical care and transport, provides specialised medical care. The rest of health care personnel, an Intensive Care Mobile Unit (nurse and emergency driver technician) and the material resources belong to the local emergency service (SUMMA 112) and do not routinely work with newborns. Emergency driver technicians in SUMMA 112 emergency service are trained in radio communications, ambulance operations and emergency response driving skills. The transport process starts with the referring hospital demanding transport for the affected newborn. The incoming call is received at SUMMA 112 call centre, where patient data are collected and the on-duty newborn transport consultant is contacted to decide the level of care to which the patient should be transported and to provide medical advice to a referring doctor. Suitable level-of-care cot is searched. The newborn transport consultant is deployed along with the dispatch of an Intensive Care Mobile team out of the 27 that are operating everyday in Comunidad de Madrid (SUMMA 112). Both assets are coordinated to arrive separately at the referring hospital to stabilise and retrieve the patient. Stabilisation process takes place according to 
Table 1 Quality indicator definitions

\begin{tabular}{|c|c|c|}
\hline Quality dimension & Indicator & Definition \\
\hline \multirow[t]{9}{*}{ Safety } & Emergency vehicle-related accidents & Rate of emergency vehicle-related accidents per total of transports \\
\hline & Emergency vehicle mechanical failure & $\begin{array}{l}\text { Rate of mechanical failures of emergency vehicle per total of } \\
\text { transports }\end{array}$ \\
\hline & In-transport mortality & Mortality rate during transport process \\
\hline & Accidental tracheal extubation & $\begin{array}{l}\text { Rate of accidental tracheal extubation during transport per total of } \\
\text { intubated patients [32] }\end{array}$ \\
\hline & Occluded or dislodged tracheal tube & $\begin{array}{l}\text { Rate of occluded or dislodged tracheal tube during transport per } \\
\text { total of intubated patients }[21,32]\end{array}$ \\
\hline & Medical device dislodgement & $\begin{array}{l}\text { Rate of medical devices, other than tracheal tube, dislodged per total } \\
\text { of transports [44] }\end{array}$ \\
\hline & Loss of monitoring & Rate of monitoring loss events per total of transports [30] \\
\hline & Equipment failure & $\begin{array}{l}\text { Rate of equipment failure (ventilator, incubator, etc.) per total of } \\
\text { transports [32] }\end{array}$ \\
\hline & $\begin{array}{l}\text { Exhaustion of medical gas supply (compressed medical } \\
\text { air, oxygen supply or nitric oxide supply) }\end{array}$ & $\begin{array}{l}\text { Rate of gas exhaustion during transport per total of transports of } \\
\text { patients undergoing respiratory support [32] }\end{array}$ \\
\hline \multirow[t]{2}{*}{ Timeliness } & Total response time $(\mathrm{min})$ & $\begin{array}{l}\text { Length of time from transport request to transport team arrival at } \\
\text { referral unit }[1,30,32]\end{array}$ \\
\hline & Mobilisation time (min) & $\begin{array}{l}\text { Length of time from transport request to team deployment from } \\
\text { base unit }[1,30,32]\end{array}$ \\
\hline \multirow[t]{6}{*}{ Effectiveness } & Stabilisation time (min) & $\begin{array}{l}\text { Length of time from transport team arrival to referring institution to } \\
\text { its departure to the receiving unit [45] }\end{array}$ \\
\hline & Systemic arterial hypotension & $\begin{array}{l}\text { Rate of mean systemic arterial hypotension below percentile } 5 \text {, per } \\
\text { chronological and gestational age, during transport process, and } \\
\text { consistent to clinical data (i.e. under vasopressor therapy, } \\
\text { presence of acidosis, oliguria) }[5,47]\end{array}$ \\
\hline & Desaturation/cyanosis episodes during transport & $\begin{array}{l}\text { Rate of oxygen desaturation }(<88 \%) \text { or cyanosis episodes during } \\
\text { transport per total of transports (cyanotic congenital heart disease } \\
\text { excluded) [32] }\end{array}$ \\
\hline & Hypoglycaemia & $\begin{array}{l}\text { Rate of blood glycaemia below } 47 \mathrm{mg} / \mathrm{dL}(2.61 \mathrm{mmol} / \mathrm{L}) \text { during } \\
\text { transport per total of transports }[18]\end{array}$ \\
\hline & Unnoticed hypothermia & $\begin{array}{l}\text { Rate of body temperature below } 36.5^{\circ} \mathrm{C} \text { at the end of the transport } \\
\text { process (HIE-affected patients undergoing therapeutic } \\
\text { hypothermia excluded) [27] }\end{array}$ \\
\hline & Favourable patient's clinical evolution & $\begin{array}{l}\text { Rate of transports with patient's TRIPS-II score stable or improving } \\
\text { during transport to total emergent transports }\end{array}$ \\
\hline \multirow[t]{2}{*}{ Efficiency } & Wrong patient triage & $\begin{array}{l}\text { Rate of patients requiring subsequent transport from the chosen } \\
\text { receiving unit per total of transports }\end{array}$ \\
\hline & Back transport & Rate of back transports per total of transports $[4,26]$ \\
\hline \multirow[t]{2}{*}{ Equity [38] } & Cot unavailability & $\begin{array}{l}\text { Rate of transport delay due to suitable level-of-care cot unavail- } \\
\text { ability per total of urgent transports }\end{array}$ \\
\hline & Newborn retrieval delays due to resource unavailability & $\begin{array}{l}\text { Rate of transport delay due to unavailability of the transport } \\
\text { resource (due to simultaneous transports that needed to be } \\
\text { attended or to a coordination error) per total of urgent transports }\end{array}$ \\
\hline \multirow[t]{3}{*}{$\begin{array}{l}\text { Patient/family-centred } \\
\text { care }\end{array}$} & Family presence during transport stabilisation process & $\begin{array}{l}\text { Rate of transports with patient's family presence (parents able to } \\
\text { see, have contact with their babies before the beginning of the } \\
\text { journey) through transport process per total of transports [12] }\end{array}$ \\
\hline & $\begin{array}{l}\text { Documented patient's family informed consent } \\
\text { procedure }\end{array}$ & $\begin{array}{l}\text { Rate of transports with documented informed consent per total of } \\
\text { transports }\end{array}$ \\
\hline & Patient's pain assessment and control & $\begin{array}{l}\text { Rate of patients with potentially painful conditions (i.e. invasive } \\
\text { ventilator support, traumatic pathology, bowel obstruction) that } \\
\text { received appropriate pharmacological pain medication during } \\
\text { transport }\end{array}$ \\
\hline
\end{tabular}

min minutes, HIE hypoxic ischemic encephalopathy, TRIPS-II score Transport Risk Index Physiological Stability II [23] 
evidence-based algorithms. Clinical data and transport times are documented on a paper-based medical record. Adverse events are registered through a specific report system.

\section{Quality indicators}

There is a lack of evidence-based scientific evidence on transport quality indicators possibly on account of the difficulties related to study design in transport medicine [33]. Quality indicators were selected and defined based on published consensus among health professionals $[6,36]$ and literature on the subject $[1,8,21,24,30,32,38]$. Some other metrics were considered clinically relevant based on the experience acquired through the development of the specialised newborn transport programme in the last 10 years and were included because of their high frequency or their impact on the performance. Twenty-four indicators were selected suiting the principles of good quality metrics $[28,29]$. Table 1 shows the definition of the quality indicators. They were classified in the six dimensions of quality suggested by the Institute of Medicine, renamed Health and Medicine Division (HMD) of the National Academies of Sciences, Engineering, and Medicine [10, 38]: safety, timeliness, effectiveness, efficiency, equity and patient-centred care. Trends in indicator values were evaluated through the study period.

The time of study was divided into two consecutive periods for data analysis: first period from 2009 to 2011 ( 3 years) and second period from 2012 to 2015 (4 years). The decision of dividing our study period in two was made to analyse the evolution of the programme's performance through time. In 2009 , major changes in human resources (including adding 2 transport consultants to the team) and material resources (new equipment) were made. The first 2 years after these major changes included training and technical problem solving. From 2011 onward, all the personnel had received their training and new protocols were developed to equipment maintenance and operation.

Transport times are defined as follows: (a) Mobilisation time is the time frame from the initial emergency call to team dispatch; (b) Response time is considered the period between call reception and the arrival of the team at patient's bedside [1], and it includes the mobilisation time; (c) Stabilisation time is defined as the time from arrival of the team to the patient's bedside until its departure from the referral hospital [7, 45].

The incidence of arterial hypotension, as a way to evaluate patient's worsening, is suggested in the literature as a quality transport indicator $[32,36]$. In newborns, there is still a challenge in defining what systemic arterial hypotension is, the best definition being the one adjusted by gestational age [47], but taking into consideration the patient's clinical context (presence of acidosis, need for inotropic support, etc.).

The severity of clinical condition in our study was assessed using TRIPS-II score $[23,25]$. It is a validated, physiology- based transport score that includes four empirically weighted items: temperature, blood pressure, respiratory status and response to noxious stimuli. TRIPS-II score may be used to assess the physiologic stability of the newborn, the lower the score, the more stable the patient is (range $0-54$ points), and as a tool to evaluate the risk of mortality at neonatal intensive care unit (NICU) admission [23]. TRIPS-II score was calculated retrospectively at three different time points: (a) at the beginning of the transport, to estimate the severity of the infant's clinical condition; (b) before team's departure at the referral hospital, to assess the stabilisation process and (c) after transport, to estimate clinical evolution.

\section{Statistical analysis}

Baseline characteristics and indicators were analysed as follows: normal distribution of continuous data was analysed using visual methods and the Shapiro-Wilk test. If normally distributed, comparison between study periods was made using Student's $t$ test, and values are described as mean and standard deviation. If continuous data were not normally distributed, comparison was made using $U$ Mann-Whitney test, and values were described as median and interquartilic range. Box plots were used to graphically represent the distribution of continuous variables. Categorical variables were defined as absolute counts and percentages and were assessed using chi square test. A two-tailed $p$ value of less than 0.05 was considered statistically significant. Stratified analysis was performed when required. When considered relevant to quality improvement, multivariate linear or logistic regression models, where appropriate, were used to investigate associations of the events of interest with the analysed factors. Factors whose association with the indicator was significant, or close to significance ( $p$ value $<0.2$ ), in the univariate analysis were entered in the multivariate model. Results of linear regression were expressed as regression coefficients, and results of logistic regression were expressed as odds ratios (ORs), with their 95\% confidence interval (CI). Stata ${ }^{\circledR} 14.2$ (Statacorp, College Station, TX, USA) was used for data analysis.

\section{Results}

During the study period, 2904 patients were retrieved, with an average of 6.4 transports/1000 births; most of them were immediate or emergency retrievals (75.92\%). Patient's epidemiologic characteristics in both periods (Table 2) were similar with small but statistically significant demographic differences among periods in birthweight and sex. There was a significantly lower prevalence of prematurity in the second period.

The evaluation of the first quality dimension, safety, was performed defining 9 indicators; their itemised rate analysis per period is expressed in Table 3. The global incidence of 
Table 2 Patient's characteristics

\begin{tabular}{|c|c|c|c|}
\hline Period of study & First period (2009-2011) & Second period (2012-2015) & Significance ( $p$ value) \\
\hline \multicolumn{4}{|l|}{ Epidemiologic variables } \\
\hline Female, $n(\%)(*)$ & $459 / 1171(39.2)$ & $736 / 1716(42.9)$ & 0.048 \\
\hline Gestational age at birth (weeks), median (range) & $38(33-40)$ & $37(33-39)$ & NS \\
\hline Birthweight (grammes), median (range) & $2800(1890-3400)$ & $3000(2290-3470)$ & 0.000 \\
\hline Age less than $24 \mathrm{~h}, n(\%)$ & $670 / 1175(57.02)$ & $807 / 1729(46.67)$ & 0.000 \\
\hline Age at transport (days), median (range) & $6(0-20)$ & $6(1-19)$ & NS \\
\hline Birthweight less than $1500 \mathrm{~g}, n(\%)$ & $188 / 1175(16)$ & $170 / 1729(9.83)$ & 0.000 \\
\hline Kind of retrieval: urgent, $n(\%)$ & $891 / 1175(75.83)$ & $1301 / 1729(75.25)$ & NS \\
\hline \multicolumn{4}{|l|}{ Severity of patient's clinical condition } \\
\hline Respiratory support (CPAP or MV), $n(\%)$ & $532 / 1175(45.28)$ & $745 / 1729(43.1)$ & NS \\
\hline TRIPS-II score at retrieval, median (range) & $17.06(16.19-17.93)^{1}$ & $17.87(17.16-18.58)^{2}$ & NS \\
\hline Vasoactive/inotropic support, $n(\%)$ & $167 / 1175(14.21)$ & $2 / 1725(14.75)$ & NS \\
\hline \multicolumn{4}{|c|}{ Type of pathology causing emergency newborn transport } \\
\hline Respiratory, $n(\%)$ & $344 / 1175(29.3)$ & $561 / 1729(32.4)$ & NS \\
\hline Prematurity, $n(\%)$ & $187 / 1175(15.9)$ & $168 / 1729(9.72)$ & $<0.001$ \\
\hline Cardiovascular, $n(\%)$ & $196 / 1175(16.7)$ & $209 / 1729(12.1)$ & NS \\
\hline Neurological, $n(\%)$ & $163 / 1175(13.8)$ & $277 / 1729(16.01)$ & NS \\
\hline Gastrointestinal, $n(\%)$ & $130 / 1175(11.1)$ & $203 / 1729(11.7)$ & NS \\
\hline
\end{tabular}

NS non-significant, CPAP continuous positive airway pressure, $M V$ mechanical ventilation, TRIPS-II Transport Risk Index Physiology Score II

*Gender of 17 patients was not specified in the transport medical chart

${ }^{1}$ TRIPS-II calculated for $n=876$

${ }^{2}$ TRIPS-II calculated for $n=1287$

safety-related events was 4.55\% (132/2904) and it descended significantly through time. The only variable independently associated to the incidence of safety issues during transport was the unavailability of neonatal retrieval resource caused by simultaneous transports (OR 5.00; CI 95\% 3.24-8.02, $p<0.001$ ).

Two indicators were identified for the dimension timeliness: mobilisation time and total response time. A significant improvement in both indicators was observed through the study period (Fig. 1a, b): time until transport team left base was lower in the second period, with a mean time of $54.3 \mathrm{~min}$ (SD 57.45) compared with the first period with a mean mobilisation time of $60.66 \mathrm{~min}$ (SD 57.23) $(p=0.001)$. Total response time showed also a significant descent: $79.57 \mathrm{~min}$ (SD 49.51) in the second period versus $88.27 \mathrm{~min}$ (SD 36.73) in the first one $(p=0.004)$. The variables independently associated to mobilisation time were as follows: daytime frame (afternoon $-9.27 \mathrm{~min} ; 95 \% \mathrm{CI}-13.8$ to $-4.72 ; p<0.001$ and night $-9.35 \mathrm{~min} ; 95 \% \mathrm{CI}-14.95$ to $-3.76 ; p=0.001$ ), diagnosis of respiratory distress $(-7.80 \mathrm{~min} ; 95 \% \mathrm{CI}-13.86$ to $-1.74 ; p=0.012$ ), diagnosis of perinatal asphyxia ($8.45 \mathrm{~min} ; 95 \% \mathrm{CI}-15.36$ to $-1.54 ; p=0.017$ ), gastrointestinal pathology $(-9.16 \mathrm{~min} ; 95 \% \mathrm{CI}-16.62$ to $-1.70 ; p=$ $0.016)$ and lack of coordination of transport assets (+ $70.31 \mathrm{~min} ; 95 \%$ CI 65.35-75.27; $p<0.001)$.
The quality metrics in the dimension of effectiveness are itemised in Table 3. Stabilisation and total transport time did not vary significantly during the whole study period (Table 3 ).

Stabilisation time was correlated to several factors: low level of complexity of the referral centre (levels IIA and IIB) (+6.97 $\mathrm{min} ; 95 \%$ CI $1.25-12.98 ; p=0.017)$, extreme prematurity (+ $7.37 \mathrm{~min}$; 95\% CI 1.41-13.33; $p=0.015)$, patient on any kind of respiratory support (+ $11.76 \mathrm{~min}$; $95 \%$ CI 7.14 $16.35 ; p<0.001)$ or vasoactive-inotropic therapy (+ $18.90 \mathrm{~min} ; 95 \%$ CI $13.19-24.61 ; p<0.001)$ and performance of any major medical intervention during transport (+ $23.19 \mathrm{~min} ; 95 \%$ CI 17.76-28.62; $p<0.001$ ).

The prevalence of arterial hypotension significantly diminished in the second period (Table 3). This indicator was associated with factors related to patient's severity of condition: cardiovascular nature of the newborn's disease (OR 2.39; $95 \%$ CI $1.23-4.63 ; p=0.01)$, perinatal asphyxia (OR $2.04 ; 95 \%$ CI $1.23-4.63 ; p=0.001)$ and the need of any respiratory support during transport (OR 6.26; 95\% CI 4.01-9.79; $p<0.001$ ).

A significant number of missing values in the variables included in TRIPS-II score, such as temperature at retrieval and systemic arterial pressure, precluded us from assessing the indicator "patient's clinical evolution".

Unnoticed hypothermia at hospital arrival occurred in $33.36 \%$ of patients $(978 / 2904)$, with a significant trend to 
descent through study time (Table 3). It was related to postnatal days of age (OR $0.99 ; 95 \%$ CI 0.985 to 0.99 ; $p=0.004$ ), gestational age in weeks (OR $0.88 ; 95 \%$ CI 0.86 to $0.90 ; p<0.001$ ), respiratory support (OR 1.55 ; $95 \%$ CI 1.26 to $1.92 ; p<0.001)$ and high complexity level of referral hospital (IIIC) (OR 0.66; 95\% CI 0.47 to 0.95 ; $p=0.023$ ). Due to the lower prevalence of prematurity in the second period, a stratified analysis was conducted (Fig. 2), and unnoticed hypothermia was still significantly less prevalent in the second period in both preterm and term newborn babies.

Efficiency was measured by 2 indicators: wrong patient triage that happened just once in the first period and none in the second, and back transport prevalence that did not change through study time (Table 3).
Equity was measured through the analysis of the delay caused by unavailability of a NICU bed of the needed level of care, and in the delay of access to the patient to the retrieval resource. The latter showed a nonsignificant increase in the second period (Table 3); the unavailability of the newborn retrieval care, due to simultaneous transports that needed to be attended or to a coordination error, was more frequent during winter (OR 1.63; 95\% CI 1.25-2.15; $p<0.001)$ and varied along with the time frame of the day, being less possible in the afternoon (OR 0.72; 95\% CI $0.55-0.94 ; p=0.017$ ) and during night shift (OR 0.45; 95\% CI $0.31-0.64 ; p<0.001)$ compared with daytime.

Patient-centred care was evaluated through 3 indicators: familial presence was stable through time of study; written informed consent fulfilment increased significantly in the second

Table 3 Quality metrics

\begin{tabular}{|c|c|c|c|c|}
\hline $\begin{array}{l}\text { Quality } \\
\text { dimension }\end{array}$ & Indicator & $\begin{array}{l}\text { First period (2009- } \\
\text { 2011) }\end{array}$ & $\begin{array}{l}\text { Second period }(2012- \\
2015)\end{array}$ & $\begin{array}{l}\text { Significance }(p \\
\text { value) }\end{array}$ \\
\hline \multirow[t]{10}{*}{ Safety } & Emergency vehicle-related accidents & $3 / 1175(0.0001)$ & $0 / 1729(0)$ & NS \\
\hline & Emergency vehicle mechanical failure & $17 / 1175(1.45)$ & $2 / 1729(0.12)$ & $p<0.001$ \\
\hline & In-transport mortality $\left({ }^{1}\right)$ & 0 & 0 & - \\
\hline & Accidental tracheal extubation & $4 / 1175(0.34)$ & $4 / 1729(0.23)$ & NS \\
\hline & Occluded or dislodged tracheal tube & $0 / 1175(0)$ & $2 / 1729(0.12)$ & NS \\
\hline & Medical device dislodgement & $3 / 1175(0.26)$ & $23 / 1729(1.33)$ & $p<0.001$ \\
\hline & Loss of monitoring & $8 / 1175(0.68)$ & $18 / 1729(1.04)$ & NS \\
\hline & Equipment failure & $42 / 1175(3.57)$ & $10 / 1729(0.58)$ & $p<0.001$ \\
\hline & Exhaustion of medical gas supply & $6 / 1175(0.51)$ & $4 / 1729(0.23)$ & NS \\
\hline & Total & $73 / 1175(6.21)$ & $59 / 1729(3.41)$ & $p<0.001$ \\
\hline \multirow[t]{2}{*}{ Timeliness } & Mobilisation time (min) $\left(^{2}\right)$ & $60.66(57.23)$ & $54.31(47.56)$ & 0.001 \\
\hline & Response time $(\mathrm{min})\left(^{2}\right)$ & $88.27(59.42)$ & $79.58(49.51)$ & 0.001 \\
\hline \multirow[t]{7}{*}{ Effectiveness } & Stabilisation time $(\min )\left({ }^{2}\right)$ & $50.59(34.22)$ & $52.35(61.10)$ & NS \\
\hline & Total transport time $(\mathrm{min})$ & $110.71(42.1)$ & $107.10(58.53)$ & NS \\
\hline & Systemic arterial hypotension (\%) & $339 / 1175(28.85)$ & $339 / 1729(19.61)$ & $p<0.001$ \\
\hline & Desaturation/cyanosis episodes during transport (\%) & $31 / 1175(2.64)$ & $54 / 1729(3.12)$ & NS \\
\hline & Hypoglycaemia (\%) & $15 / 1175(1.28)$ & $23 / 1729(1.33)$ & NS \\
\hline & Unnoticed hypothermia $(\%)$ & $461 / 1175(39.23)$ & $517 / 1729(29.9)$ & $p<0.001$ \\
\hline & Favourable patient's clinical evolution $(\%)\left({ }^{3}\right)$ & $57 / 74(77.03)$ & $170 / 228(74.56)$ & NS \\
\hline Efficiency & Back transport & $131 / 1175(11.15)$ & $170 / 1729(9.83)$ & NS \\
\hline \multirow[t]{2}{*}{ Equity } & Delay caused by unavailability of transport resource $\left({ }^{2}\right)$ & $147 / 891(16.5)$ & $222 / 1301(17.1)$ & NS \\
\hline & $\begin{array}{l}\text { Delay caused by temporary unavailability of } \\
\text { appropriate-level } \cot \left({ }^{2}\right)\end{array}$ & $2 / 1175(0.17)$ & $0 / 1729(0)$ & NS \\
\hline \multirow{3}{*}{$\begin{array}{l}\text { Patient-centred } \\
\text { care }\end{array}$} & Family presence during stabilisation process & $1128 / 1175(96)$ & $1669 / 1729(96.5)$ & NS \\
\hline & Documented patient's family informed consent procedure & $931 / 1175(79.2)$ & $1438 / 1729(83.17)$ & 0.007 \\
\hline & Patient's pain assessment and control $\left({ }^{4}\right)$ & $211 / 399(52.88)$ & $260 / 484(53.72)$ & NS \\
\hline
\end{tabular}

NS nonsignificant

$\left({ }^{1}\right)$ During the whole period, five patients in critical condition at transport team arrival suffered cardiorespiratory arrest, unresponsive to resuscitation, before the transport process begun and died at the referral centre

$\left({ }^{2}\right)$ Only urgent transports considered

$\left({ }^{3}\right)$ Missing values for TRIPS-II at retrieval or at admission

$\left({ }^{4}\right)$ Rate of patients with potentially painful conditions that received appropriate pharmacological pain medication during transport 


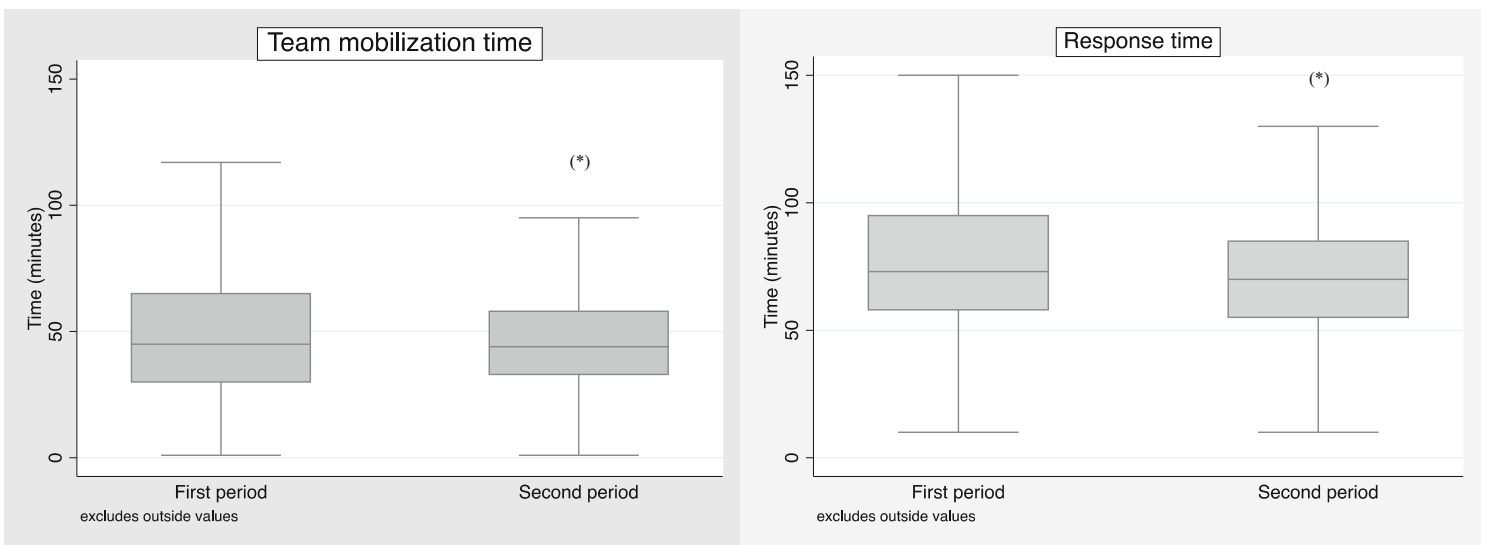

Fig. 1 Team mobilisation time (a) and response time (b) comparing two periods of study. $* p<0.05$

period, while appropriate pain control in newborns with potentially painful pathology was lower in the second period (Table 3 ).

\section{Discussion}

The present study summarises the quality evaluation of a newborn transport system using twenty-four quality indicators; some had been previously defined in literature and some were designated based on relevance considering the programme's experience. The study shows how quality evaluation in newborn transport is feasible, and how some quality metrics need to be adapted to or defined specifically for the newborn population.

Newborn patients have unique characteristics inherent to their size, maturity and pathology. This may affect the performance of the transport programme itself $[1,6,32,44]$. Gestational age affects significantly some of the transport performance measures in the effectiveness domain: stabilisation time and unintended hypothermia [1, 3, 13, 27, 32]. In the present study, unnoticed hypothermia was outstandingly more frequent than reported in other studies [37] and similar to others [42], and prevalent in preterm and term babies, but significantly descended in the second period probably reflecting a better performance. Besides, the adequate definition for systemic arterial hypotension in newborns is yet to be established, but it is clear that gestational age needs to be taken into account [47].

Some of the indicators used in the present study were selected because they represent an important matter of newborn transport, such as some patient-centred indicators. Newborn pain evaluation during transport lacks the appropriate tools as there is none validated in this context [19]. In our programme, pain perception during transport is determined by the clinician and the pharmacological sedation-analgesia is provider-driven. Pain control in pain-susceptible situations seemed more appropriate as an indicator than pain evaluation using validated tools, as the latter does not entail right management. Patient-centred indicators show internal validation with consistent values through time. Their usefulness is yet to be determined, based on the transport's unit quality policy, if social and psychological aspects of the team performance are added to definition of quality [14].

Patient's clinical evolution during transport, defined relying on the change in the patient's TRIPS-II score during transport, has been previously defined in published literature as a quality metric $[11,17]$. The transport process can influence greatly in the patient's clinical status, especially in preterm newborns, but the contribution to the transport process itself is still unclear $[9,16,43]$. A quality metric achievable during transport, such as TRIP-II score, with prognostic implications can be of great use to evaluate the transport team's performance and, after adjusting for population characteristics, to benchmarking. Regrettably, due to the retrospective nature of the present study, the significant amount of missing values of some of the items included in TRIPS-II score made its calculation impossible; this circumstance highlights the importance of data registry to quality control.

In Spain, there is universal access to health care. One of the goals of a highly regionalised neonatal care system is to guarantee equity in terms of access to appropriate care. Equity in newborn transport in this study was estimated using the delay of access to the patient to the retrieval resource due to the transport team being busy. This was an indicator more prevalent in winter, probably due to bronchiolitis annual epidemic and during morning time frame because transport overlapping resulted in an increase in response time. Minimising the response time is a prime goal in any transport service [1], especially since it may have a negative effect on the patient, as shown in our study with a significant increase in adverse events. Safety events occurred, which is consistent with the published literature [24, 30, 32]. Safety events in the present study improved through time.

There is not an ideal and single model of transport system [26]. It has to be adapted to the regional available resources [46]. Madrid's newborn transport programme infrastructure is designed to share resources with the local emergency transport system (SUMMA 112), and this study shows how this may limit the performance of the newborn transport programme in some quality areas: dislodgement of medical devices probably 
Fig. 2 Unnoticed hypothermia stratified by term/preterm babies in both periods

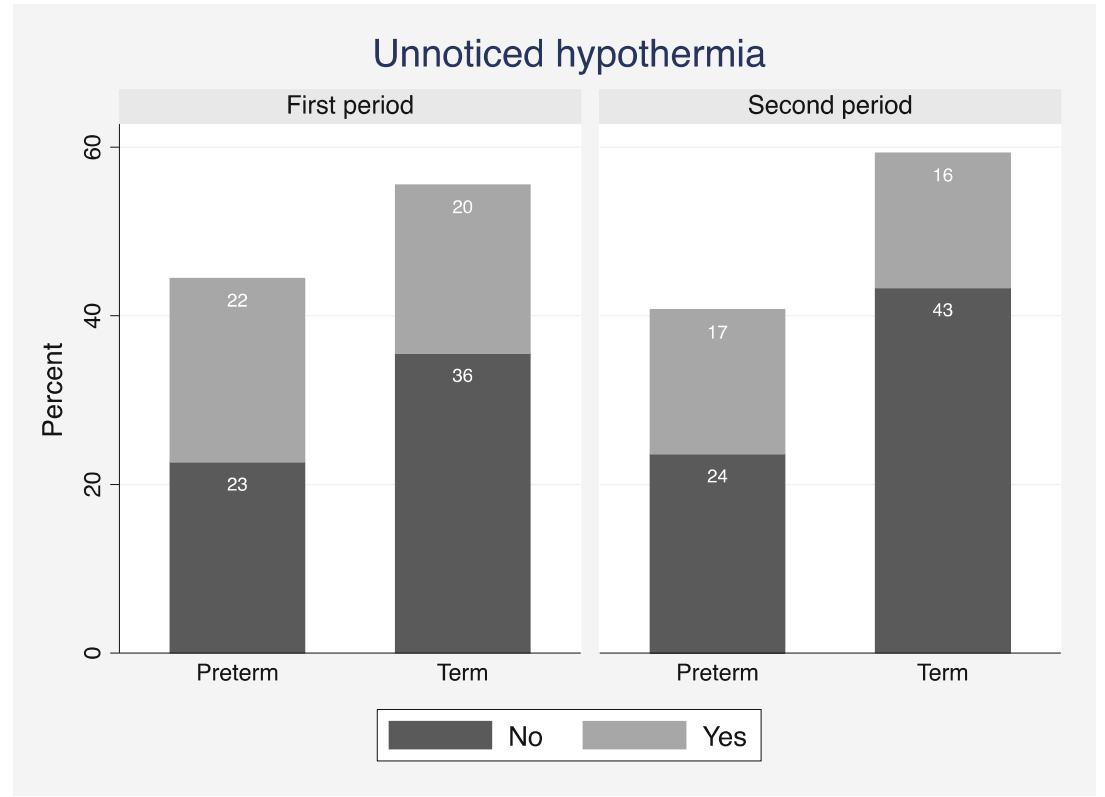

due to lack of training of the transport nurse in newborn practice, response time caused by concurrence of transports, etc.

There are some limitations to the study, the first one being the lack of external validation of the suggested indicators. The retrospective evaluation in two consecutive periods of different lengths may affect the strength of the results; the decision of the period division was made upon major internal changes that were performed in the transport protocol through the first period (2009), in order to evaluate if this affected the performance of the service. The patient's epidemiologic characteristics and main diagnosis were quite similar through the time study except for the fact that prematurity significantly descended in the second period. To adjust for this confounding factors, logistic regression and stratification was performed. The significant differences found in the quality metrics between the two periods studied may reflect an improvement (i.e. response time) or a worsening (i.e. medical device dislodgement rate) in quality of service but, due to the design and the retrospective nature of the study, it could reflect the influence of other factors or lack of registry of an indicator by transport personnel [30]. The observational nature of the study design limits the possibility of drawing robust conclusions from the data. Observational studies, though, illustrate the real daily conditions of the situation evaluated [33]: the newborn transport process. Some of the indicators, such as TRIPS-II score, were obtained retrospectively with significant missing values probably reflecting a lack of registry of normal values [16].

Quality metrics definition can be a challenging task, and the ideal way to select and define them is still to be agreed upon [41]. Quality indicators for paediatric and newborn transport have been defined in previous studies using different methodologies, the expert panel consensus, Delphi method, being the most accepted $[6,32,36]$. Despite increasing international interest for improving the quality of health care, there is still a great variation in the kind of care delivered during newborn transport around the world. It is important to benchmark and compare the performance of different transport systems in order to seek for excellence, but it is also important to choose indicators adapted to the population's characteristics, newborns in this case, and suitable to assess the quality of team performance through time. More clinical research is needed in newborn transport quality metrics because there is still paucity of data on this matter.

\section{Conclusions}

Quality evaluation through the definition of specific metrics in newborn transport is feasible. The chosen indicators should be defined specifically or adjusted for newborn population in order to measure the real performance of the transport service and to facilitate benchmarking.

Acknowledgements We thank all the staff in the SUMMA 112 emergency service for their role in making this collaborative specialised newborn retrieval service work and the neonatology transport consultants for data gathering and adverse event reporting.

Authors' Contributions Itziar Marsinyach Ros contributed in data collection, statistical analysis and preparation of the manuscript.

Laura Sánchez has contributed in data collection.

Ana Sánchez has contributed in the manuscript review and its preparation.

Rocío Mosqueda has contributed in data collection and manuscript preparation.

Menchu has contributed in data collection and manuscript preparation.

Maria José has contributed in the manuscript review.

Dolores Elorza has contributed in the manuscript review and its preparation.

Manuel approved the final version of the manuscript. 


\section{Compliance with ethical standards}

Conflict of interest The authors declare that they have no conflicts of interest.

Ethical approval The data collection from medical charts for this study was approved by the Ethics Review Board of SUMMA 112. Due to the observational nature of this work, the requirement for individual informed consent was waived.

\section{References}

1. Abdel-Latif ME, Berry A 2009 Analysis of the retrieval times of a centralised transport service, New South Wales, Australia. Arch Dis Child . NETS, Westmead, NSW 2145, Australia. 94:282-6. Available from: http://www.ncbi.nlm.nih.gov/pubmed/18927147

2. Akula VP, Hedli LC, Van Meurs K, Gould JB, Peiyi K, Lee HC (2019) Neonatal transport in California: findings from a qualitative investigation. Journal of Perinatology. https://doi.org/10.1038/ s41372-019-0409-7

3. Arora P, Bajaj M, Natarajan G, Arora NP, Kalra VK, Zidan M, Shankaran S (2014) Impact of interhospital transport on the physiologic status of very low-birth-weight infants. Am J Perinatol 31: 237-244

4. Attar MA, Bratton SL (2007) Effect of back transport on readmissions and follow-up care. Pediatrics 120:455-457 Available from: http://www.ncbi.nlm.nih.gov/pubmed/17671080

5. Batton B, Li L, Newman NS, Das A, Watterberg KL, Yoder BA, Faix RG, Laughon MM, Stoll BJ, van Meurs K, Carlo WA, Poindexter BB, Bell EF, Sánchez PJ, Ehrenkranz RA, Goldberg RN, Laptook AR, Kennedy KA, Frantz ID 3rd, Shankaran S, Schibler K, Higgins RD, Walsh MC, Eunice Kennedy Shriver National Institute of Child Health \& Human Development Neonatal Research Network (2013) Use of antihypotensive therapies in extremely preterm infants. Pediatrics 131:e1865-e1873. https://doi.org/10.1542/peds.2012-2779

6. Bigham MT, Schwartz HP 2013 Ohio neonatal/pediatric transport quality C. Quality metrics in neonatal and pediatric critical care transport: a consensus statement. Pediatr Crit Care Med. Department of Pediatrics, Akron Children's Hospital, Akron, OH, USA.14:518-24. Available from: http://www.ncbi.nlm.nih.gov/ pubmed/23867429, mbigham@chmca.org

7. Borrows EL, Lutman DH, Montgomery MA, Petros AJ, Ramnarayan P 2010 Effect of patient- and team-related factors on stabilization time during pediatric intensive care transport. Pediatr Crit Care Med. Children's Acute Transport Service (CATS), London, United Kingdom. 11:451-6. Available from: http://www. ncbi.nlm.nih.gov/pubmed/20453701

8. Browning Carmo KA, Williams K, West M, Berry A 2008 A quality audit of the service delivered by the NSW Neonatal and Paediatric Transport Service. J Paediatr Child Health. NETSMoving Intensive Care for Kids, Children's Hospital at Westmead, New South Wales, Australia. 44:253-72. Available from: http://www.ncbi.nlm.nih.gov/pubmed/18036145

9. Chien LY, Whyte R, Aziz K, Thiessen P, Matthew D, Lee SK, et al. 2001 Improved outcome of preterm infants when delivered in tertiary care centers. Obstet Gynecol [Internet]. Department of Pediatrics, University of British Columbia, Vancouver, British Columbia, Canada. 98:247-52. Available from: http://www.ncbi. nlm.nih.gov/pubmed/11506840

10. Committee on the Quality of Health Care in America I of M 2001 Crossing the quality chasm: a new health system for the $21 \mathrm{st}$ century. Crossing the Quality Chasm: A New Health System for the 21st Century.

11. Davidson L.A., Carlisle M., Utarnachitt R., Avaiusini L. Bridges E 2018 Utilizing the Transport Risk Index of Physiologic Stabilitiy Version II (TRIPS II): establishing a baseline of the neonates transported by Airlift Northwest. Pediatrics. Volumen 141. Issue 1 MeetingAbstract

12. Davies J, Tibby SM, Murdoch IA 2005 Should parents accompany critically ill children during inter-hospital transport? Arch Dis Child. Department of Paediatric Intensive Care, Guy's and Saint Thomas' NHS Foundation Trust, London, UK. 90:1270-3. Available from: http://www.ncbi.nlm.nih.gov/pubmed/15890692

13. de Almeida MF, Guinsburg R, Sancho GA, Rosa IR, Lamy ZC, Martinez FE, et al. 2014 Hypothermia and early neonatal mortality in preterm infants. J Pediatr [Internet]. Division of Neonatal Medicine, Universidade Federal de Sao Paulo/Escola Paulista de Medicina, Sao Paulo, SP, Brazil. Division of Neonatal Medicine, Universidade Federal de Sao Paulo/Escola Paulista de Medicina, Sao Paulo, SP, Brazil. Electronic address: r; 164:271-5 e1. Available from: http://www.ncbi.nlm.nih.gov/pubmed/24210925

14. Donabedian A. 1988 The quality of care. How can it be assessed? JAMA. University of Michigan School of Public Health, Ann Arbor 260:1743-8. Available from: http://www.ncbi.nlm.nih.gov/ pubmed $/ 3045356$

15. Donabedian A (1966) Evaluating the quality of medical care. The Milbank Memoral Fund Quarterly 44:166-203

16. Eliason SH, Whyte H, Dow K, Cronin CM, Lee S, Canadian Neonatal N 2013 Variations in transport outcomes of outborn infants among Canadian neonatal intensive care units. Am J Perinatol. University of British Columbia, Vancouver, British Columbia, Canada. 30:377-82. Available from: http://www.ncbi. nlm.nih.gov/pubmed/22918675

17. Gente M, Lallo D Di, Franco F, Aufieri R, Paolillo P, Curtis M De (2015) Stabilization of the critically ill neonate awaiting transport. Italian Journal of Pediatrics. https://doi.org/10.1186/1824-7288-41s1-a15

18. Gunz AC, Dhanani S, Whyte H, Menon K, Foster JR, Parker MJ, McNally JD (2014) Identifying significant and relevant events during pediatric transport: a modified Delphi study. Pediatr Crit Care Med. https://doi.org/10.1097/PCC.0000000000000171

19. Harrison C, McKechnie L 2012 How comfortable is neonatal transport? Acta Paediatr. Department of Neonatal Medicine, Leeds Teaching Hospitals Trust, UK. 101:143-7. Available from: http:// www.ncbi.nlm.nih.gov/pubmed/21913977, catherine.harrison@ leedsth.nhs.uk

20. Instituto Nacional de Estadistica Instituto Nacional de Estadística.n.d. Spanish Statistical Office. Available from: http:// www.ine.es/INEbase/Demografía_y_población/Cifras_de_ población_y_censos_demográficos. [cited 1 Nov 2018 ].

21. Kanter RK, Tompkins JM 1989 Adverse events during interhospital transport: physiologic deterioration associated with pretransport severity of illness. Pediatrics [Internet]. Department of Pediatrics, State University of New York, Health Science Center, Syracuse.84:43-8. Available from: http://www.ncbi.nlm.nih.gov/ pubmed/2740177

22. Karlsen KA, Trautman M, Price-Douglas W, Smith S 2011 National survey of neonatal transport teams in the United States. Pediatrics. Primary Childrens Medical Center, Salt Lake City, Utah 84113, USA. 128:685-91. Available from: http://www.ncbi.nlm.nih.gov/ pubmed/21949141, kristine.karlsen@imail.org

23. Lee S, Aziz K, Dunn M, Clarke M, Kovacs L, Ojah C, Ye XY, Canadian Neonatal Network (2013) Transport Risk Index of Physiologic Stability, version II (TRIPS-II): a simple and practical neonatal illness severity score. Am J Perinatol 30:395-400

24. Lim MT, Ratnavel N 2008 A prospective review of adverse events during interhospital transfers of neonates by a dedicated neonatal 
transfer service. Pediatr Crit Care Med [Internet]. Royal London Hospital, London, United Kingdom; 9:289-93. Available from: http://www.ncbi.nlm.nih.gov/pubmed/18446101, miketclim@ yahoo.co.uk;

25. Lucas da Silva PS, Euzebio de Aguiar V, Reis ME 2012 Assessing outcome in interhospital infant transport: the transport risk index of physiologic stability score at admission. Am J Perinatol. Pediatric Intensive Care Unit, Department of Pediatrics, Hospital Brigadeiro, Sao Paulo, Brazil.psls.nat@terra.com.br; 29:509-14. Available from: http://www.ncbi.nlm.nih.gov/pubmed/22495897

26. Lupton BA, Pendray MR (2004) Regionalized neonatal emergency transport. Semin Neonatol 9:125-133

27. Lyu Y, Shah PS, Ye XY, Warre R, Piedboeuf B, Deshpandey A, et al 2015 Association between admission temperature and mortality and major morbidity in preterm infants born at fewer than 33 weeks' gestation. JAMA Pediatr [Internet]. Maternal-Infant Care Research Centre, Mount Sinai Hospital, Toronto, Ontario, Canada2Department of Pediatrics, University of Toronto, Toronto, Ontario, Canada3Capital Institute of Pediatrics, Beijing, China. Maternal-Infant Care Research Centre, Mount Sin; 169:e150277. Available from: http://www.ncbi.nlm.nih.gov/pubmed/25844990

28. Mainz J (2003) Defining and classifying clinical indicators for quality improvement. Int J Qual Health Care. https://doi.org/10.1093/ intqhe/mzg081

29. Mainz J (2003) Developing evidence-based clinical indicators: a state of the art methods primer. Int J Qual Health Care. https://doi. org/10.1093/intqhe/mzg084

30. Moss SJ, Embleton ND, Fenton AC (2005) Towards safer neonatal transfer: the importance of critical incident review. Arch Dis Child 90:729-732

31. Profit J, Zupancic JAF, Gould JB, Pietz K, Kowalkowski MA, Draper D, et al 2013 Correlation of neonatal intensive care unit performance across multiple measures of quality of care. JAMA Pediatrics

32. Ramnarayan P. 2009 Measuring the performance of an interhospital transport service. Arch Dis Child. Children's Acute Transport Service, London, UK. RamnaP@gosh.nhs.uk;94:414 6. Available from: http://www.ncbi.nlm.nih.gov/pubmed/ 19174393

33. Reimer AP, Daly BJ (2014) Ethical considerations for conducting a randomized controlled trial in transport. Air Med J 33:274-279

34. Rite Gracia S, Fernández Lorenzo JR, Echániz Urcelay I, Botet Mussons F, Herranz Carrillo G, Moreno Hernando J et al (2013) Niveles asistenciales y recomendaciones de mínimos para la atención neonatal. Anales de Pediatria 79:56-64

35. Scanlon MC, Mistry KP, Jeffries HE 2007 Determining pediatric intensive care unit quality indicators for measuring pediatric intensive care unit safety. Pediatr Crit Care Med [Internet]. Department of Pediatrics, Critical Care, Medical College of Wisconsin, Milwaukee, WI, USA. 8:S3-10. Available from: http://www.ncbi. nlm.nih.gov/pubmed/17496830

36. Schwartz HP, Bigham MT, Schoettker PJ, Meyer K, Trautman MS, Insoft RM, et al 2015 Quality metrics in neonatal and pediatric critical care transport: a National Delphi Project. Pediatr Crit Care Med. 1Division of Emergency Medicine, Department of Pediatrics, Cincinnati Children's Hospital, University of Cincinnati School of Medicine, Cincinnati, OH. 2Division of Critical Care Medicine, Department of Pediatrics, Akron Children's Hospital, Northeast Ohi, 16:711-7. Available from: http://www.ncbi.nlm.nih.gov/ pubmed/26181297

37. Skiold B, Stewart M, Theda C 2015 Predictors of unfavorable thermal outcome during newborn emergency retrievals. Air Med J .
Newborn Emergency Transport Service, Royal Children's Hospital, Melbourne, Victoria, Australia; Royal Women's Hospital, Melbourne, Victoria, Australia. Newborn Emergency Transport Service, Royal Children's Hospital, Melbourne, Victoria, Australia; Royal W; 34:86-91. Available from: http:// www.ncbi.nlm.nih.gov/pubmed/25733114

38. Slonim AD, Pollack MM 2005 Integrating the Institute of Medicine's six quality aims into pediatric critical care: relevance and applications. Pediatr Crit Care Med. Children's National Medical Center and The George Washington University School of Medicine, Washington, DC, USA;6:264-9. Available from: http://www.ncbi.nlm.nih.gov/pubmed/15857522

39. Soliman Y, Paul R, Pearson K, Al Shaikh B, Thomas S, Yusuf K (2019) Neonatal transport services, a cross-sectional study. J Matern Fetal Neonatal Med. https://doi.org/10.1080/14767058.2019. 1618823

40. SQUIRE guidelines 2015 SQUIRE. Explanation and elaboration of SQUIRE 2.0 guidelines. Available from: http://www.squirestatement.org. [cited 2018 Nov 11]

41. Stroud MH, Trautman MS, Meyer K, et al (2013) Pediatric and neonatal interfacility transport: results from a national consensus conference. Pediatrics 132:359-366

42. Sutcuoglu S, Celik T, Alkan S, Ilhan O, Ozer EA 2015 Comparison of neonatal transport scoring systems and transport-related mortality score for predicting neonatal mortality risk. Pediatr Emerg Care. From the Tepecik Teaching and Research Hospital, Neonatal Intensive Care Unit, Izmir, Turkey. 31:113-6. Available from: http://www.ncbi.nlm.nih.gov/pubmed/25654677

43. Towers C V, Bonebrake R, Padilla G, Rumney P 2000 The effect of transport on the rate of severe intraventricular hemorrhage in very low birth weight infants. Obstet Gynecol [Internet]. Long Beach Memorial Women's Hospital, California, USA. 95:291-5. Available from: http:/www.ncbi.nlm.nih.gov/pubmed/10674596

44. Whitfield JM (1995) Audit of neonatal intensive care transport. Arch Dis Child Fetal Neonatal Ed 72:F79-F80 Available from: http://www.ncbi.nlm.nih.gov/pubmed/7743294

45. Whitfield JM, Buser MK 1993 Transport stabilization times for neonatal and pediatric patients prior to interfacility transfer. Pediatr Emerg Care. Children's Hospital, Denver, C0.9:69-71. Available from: http://www.ncbi.nlm.nih.gov/pubmed/8483782

46. Woodward GA, Insoft RM, Pearson-Shaver AL, Jaimovich D, Orr RA, Chambliss R, et al. 2002 The state of pediatric interfacility transport: consensus of the second National Pediatric and Neonatal Interfacility Transport Medicine Leadership Conference. Pediatr Emerg Care [Internet]. Children's Hospital of Philadelphia/ University of Pennsylvania School of Medicine Philadelphia, Pennsylvania 19104, USA. 18:38-43. Available from: http:/ www.ncbi.nlm.nih.gov/pubmed/11862139, WoodwardG@email. chop.edu;

47. Zubrow AB, Hulman S, Kushner H, Falkner B 1995 Determinants of blood pressure in infants admitted to neonatal intensive care units: a prospective multicenter study. Philadelphia Neonatal Blood Pressure Study Group. J Perinatol. Division of Neonatology, Albert Einstein Medical Center, Philadelphia, Pa. 19141-3098, USA. 15:470-9. Available from: http://www.ncbi. nlm.nih.gov/pubmed/8648456

Publisher's note Springer Nature remains neutral with regard to jurisdictional claims in published maps and institutional affiliations. 